REVISTA DE DERECHO UNED, NÚM. 9, 2011

\title{
SOBRE LA CONSTITUCIONALIDAD DE CIERTOS SISTEMAS DE ACCESO A LA FUNCIÓN PÚBLICA DOCENTE NO UNIVERSITARIA
}

\author{
JAVIER SÁNCHEZ PiQuero \\ DEA. Doctorando de Derecho Político de la UNED \\ Profesor de Enseñanza Secundaria, especialidad Formación y \\ Orientación Laboral
}

Resumen: El acceso a la función pública docente ha venido padeciendo a lo largo de los años, similares prácticas restrictivas al derecho a la igualdad que en el resto de la función pública española. La creación de grandes bolsas de maestros y profesores interinos, derivada de un funcionamiento inadecuado de las administraciones educativas, ha sido la excusa perfecta para validar sistemas excepcionales de acceso, con evidente merma de los principios constitucionales de igualdad, mérito y capacidad.

Este problema, lejos de resolverse pasados ya más de treinta años desde la aprobación de la Constitución, está aún plenamente vigente. Prueba de ello es el sistema transitorio de acceso a la función docente de la actual Ley Orgánica de Educación, que ha estado en vigor estos últimos años y que es objeto de análisis en este trabajo.

Palabras clave: Igualdad, mérito, capacidad, acceso función pública, educación.

Abstract: Along the years accession to the teaching civil service has been suffering similar restriction practices to the right to equality, than the rest of the Spanish civil services. The creation of large pools of temporary teachers, due to inadequate running of the education authorities, has been de perfect excuse to validate exceptional systems of accession, with the evident decrease of the constitutional principles 
of equality, merit and ability. This problem, after more than thirty years without been solved, since the adoption of the Constitution, is still in force. In proof of it is the transitory system of accession to the teaching civil service of the current Education Law, which has been in force in recent years, and it is the subject of analysis in this work.

Key words: Equality, merit, ability, civil service access, education.

Sumario: Introducción.-I. Sistemas de acceso directo.-II. Pruebas restringidas y procesos de funcionarización.-III. Otros sistemas excepcionales de acceso: la antigüedad como mérito preferente.-IV Devaluación del principio constitucional de capacidad mediante la desnaturalización de la fase de oposición.-V. Análisis del sistema transitorio de acceso a la función docente de la actual Ley Orgánica de Educación.-V.1. De nuevo un sistema excepcional de acceso a la función docente.-V.2. Devaluación de la fase de oposición en el sistema transitorio de la LOE.-V.3. Exención de prueba selectiva a los funcionarios interinos, ¿vulneración del derecho a la igualdad?.-VI. Conclusiones.

\section{INTRODUCCIÓN}

Sería ocioso destacar en estas líneas la trascendencia que el derecho a la igualdad en el acceso a la función pública ha tenido en el desarrollo de los Estados democráticos modernos. El profesor SáNCHEZ MORÓN ${ }^{1}$ lo califica como «uno de los pilares sobre los que se asienta el Estado de derecho en todos los regímenes democráticos», pues recoge, no sólo un derecho subjetivo fundamental a la igualdad de oportunidades en el acceso a la función pública, sino también un principio que ha de guiar con letras de oro el funcionamiento de todo Estado democrático de derecho.

Como señala nuestra Constitución, «la Administración Pública sirve con objetividad a los intereses generales», y ello no es posible sin un funcionariado profesional, seleccionado conforme a los principios de igualdad, mérito y capacidad, que asegure los fines del Estado de derecho, con independencia de los avatares políticos.

Prueba de lo anterior, es la inclusión del derecho a la igualdad en el acceso a la función pública como uno de los derechos fundamentales reconocidos en nuestra Constitución, lo que implica dotarle de

1 SÁnchez Morón, M., en VV.AA. Comentarios a la Constitución Española de 1978, Vol II (Alzaga Villaamil, O. Dir.), Madrid: Edersa, 1997, pág. 667. 
un conjunto de mecanismos especiales de tutela jurídica, entre los que destaca la posibilidad de recurrir en amparo ante el Tribunal Constitucional.

No obstante, han sido muchas las voces cualificadas que, a lo largo de estos años de vigencia de nuestra Carta Magna, han advertido de los peligros que permanentemente acechan a la efectividad de este derecho fundamental ${ }^{2}$, hasta el punto de considerar que esta cuestión es todavía una «asignatura pendiente para nuestra democracia» ${ }^{3}$.

Dentro de la función pública española, el ámbito de la enseñanza no universitaria constituye uno de los sectores más trascendentes, tanto por la tarea que tiene encomendada, como por la cantidad de recursos humanos que precisa para prestar un adecuado servicio. En España la mayor parte de la enseñanza primaria y secundaria descansa en un sistema público, integrado por miles de funcionarios, que son los encargados de la trascendental tarea de instruir y educar a nuestros niños y jóvenes. En la actualidad hay más de 400.000 funcionarios en el ámbito docente no universitario ${ }^{4}$, y todos los años se convocan nuevos procesos selectivos para ingresar en los distintos cuerpos de la función pública docente.

No es por ello superfluo resaltar la importancia que para este país tiene que los procesos de selección se hagan con un escrupuloso respeto a los principios constitucionales de igualdad, mérito y capacidad, pues de ello no sólo depende la calidad y eficacia de una educación cada vez más trascendental en el devenir de este país, sino los derechos y esperanzas de miles de personas que aspiran a ingresar en la función pública docente.

Como veremos a lo largo de este trabajo, el acceso a la función pública docente ha venido padeciendo a lo largo de estos años, similares

${ }^{2}$ Como ejemplo de las muchas reticencias que diversos autores han formulado durante estos años a la plena efectividad del derecho consagrado en el art. 23.2, es ilustrativa la opinión de Parada VÁzouez, J. R., en Derecho Administrativo II, Organización y empleo público, Madrid: Marcial Pons, 2007, 477 y ss.

${ }^{3}$ SÁnchez Morón, M., «Igualdad, mérito y capacidad en el empleo público», en VV.AA., El principio de igualdad, Madrid: Dykinson 2000, pág. 147. Igual consideración merece el estado actual del tema objeto de este trabajo a MARTín-RETorTiLLo, L., quien analiza de manera muy crítica la pervivencia del spoil system en la España actual en Méritos o botín y otros retos jurídicos de la democracia, Pamplona: Aranzadi, 2000.

${ }^{4}$ Datos de junio del 2010, según el boletín estadístico del personal al servicio de las Administraciones Públicas del Registro Central de Personal del Ministerio de Política Territorial y Administración Pública. 
prácticas restrictivas al derecho a la igualdad que en el resto de la función pública. La creación de grandes bolsas de maestros y profesores interinos, derivada de un funcionamiento inadecuado de las administraciones educativas, ha sido la excusa perfecta para validar sistemas excepcionales de acceso, con evidente merma de los principios constitucionales de igualdad, mérito y capacidad.

Este problema, lejos de resolverse pasados ya más de treinta años desde la aprobación de la Constitución, está aún plenamente vigente. Prueba de ello es el sistema transitorio de acceso a la función docente de la actual Ley Orgánica de Educación, que ha estado en vigor estos años y que es objeto de análisis en este trabajo.

\section{SISTEMAS DE ACCESO DIRECTO}

Los sistemas de acceso directo a la función pública, esto es, aquellos en los que se determina el ingreso automático sin ningún tipo de prueba selectiva que permita verificar las capacidades y méritos de los candidatos, fueron proscritos por el Tribunal Constitucional en la STC 302/1993, de 21 de octubre. En dicha sentencia se enjuició un recurso de inconstitucionalidad contra la disposición transitoria sexta de la Ley 6/1985 de Ordenación de la Función Pública de la Junta de Andalucía, en la que se establecía la integración ope legis y de manera automática en la función pública andaluza, sin pruebas específicas de acceso, de determinado personal con contratos administrativos y funcionarios interinos ${ }^{5}$. El Tribunal consideró que la promoción interna de los funcionarios a través del trabajo no puede confundirse con una patente para excluir la vigencia de estos preceptos constitucionales (arts. 23.2 y $103.3 \mathrm{CE}$ ) ni siquiera temporal y excepcionalmente, puesto que nada permite al legislador estatal o autonómico transgredir los límites que la Constitución impone a su libertad de configuración normativa y menos cuando está en juego un derecho con rango de fundamental como es la igualdad de acceso de todos los ciudadanos a las funciones públicas. Por ello la sentencia determina que «es patente que el mandato de integración automática, sin efec-

5 El texto del precepto impugnado es el siguiente: «El personal con contrato administrativo afectado por el Decreto 153/1982, de 22 de diciembre y que en la actualidad se encuentran prestando sus servicios activos en la Junta de Andalucía, adquirirá automáticamente a la entrada en vigor de la presente Ley, la categoría de funcionario de carrera de la Administración en la Comunidad Autónoma Andaluza. A efectos de antigüedad y trienios, a dicho personal le son reconocidos los servicios prestados en la Administración de la Junta de Andalucía con anterioridad a la adquisición de la condición de funcionario de la misma.» 
tuar pruebas objetivas de reclutamiento, aunque fueran específicas o de turno restringido, traspasa los límites impuestos, para la racionalización de las Administraciones públicas, en la Disposición transitoria sexta de la Ley de Medidas de la Función Pública, que permite convocar pruebas específicas en ciertos casos y con las limitaciones temporales allí señaladas, pero en modo alguno habilita a una integración automática que erija la antigüedad de los servicios prestados a la Administración en título único y excluyente de otros que legitime el acceso a la función pública.»

Sin embargo, en el ámbito docente operó un sistema de acceso automático, sin prueba de selección alguna, coexistiendo con la Constitución hasta la llegada de la Ley 30/1984 de Medidas para la Reforma de la Función Pública. Así la Ley 14/1970 General de Educación estableció, en su artículo 110.1, el acceso al cuerpo de profesores de educación general básica directamente desde la escuelas universitarias correspondientes, sin necesidad de pruebas posteriores, en los casos de expedientes sobresalientes a lo largo de todos los estudios ${ }^{6}$. No es difícil imaginar las repercusiones que un sistema de esta naturaleza pudo tener en la efectiva igualdad en el acceso a la función pública. Los candidatos se elegían repartiéndose el cupo por provincias y universidades según el número de matriculados, por lo que maestros de algunas universidades no accedían a pesar de tener mayor puntuación que los de otras. Además fue patente que algunas universidades hinchaban las notas de sus alumnos para alcanzar más prestigio y matrícula. Es evidente que en un sistema como el descrito las garantías para la efectiva aplicación de los principios de igualdad, mérito y capacidad eran más bien escasas. Por ello el Tribunal Supremo, en la STS 359/1988, de 25 de enero, determinó que el acceso directo regulado en el art. 110 de la Ley General de Educación era contrario a la Ley. Paradójicamente este sistema no fue rechazado por su incompatibilidad con la Constitución -de hecho el Tribunal Constitucional nunca llegó a manifestarse al respecto-, sino "por resultar afectado por las normas estatutarias de carácter general que incorpora la Ley 30/1984.»

\section{PRUEBAS RESTRINGIDAS Y PROCESOS DE FUNCIONARIZACIÓN}

Un problema recurrente en los sistemas de acceso a la función pública española lo presentan las llamadas pruebas restringidas y su

${ }^{6}$ Dicho artículo fue desarrollado por el Decreto 375/1974, de 7 de febrero, por el que se regula el acceso al cuerpo de profesores de educación general básica. 
posible incompatibilidad con el derecho a acceder en condiciones de igualdad a las funciones públicas. Por pruebas restringidas nos referimos fundamentalmente a aquellos procesos de selección que tienen por destinatarios a funcionarios interinos, con la consiguiente exclusión de los ciudadanos que, reuniendo los requisitos generales, carezcan de dicha vinculación con la Administración.

Durante los primeros años de democracia, la función pública española adolecía de una saturación de funcionarios interinos que desarrollaban su trabajo en unas condiciones laborales precarias. Esta situación era incluso de mayor intensidad en la función docente, como consecuencia del acceso a la educación de un número elevado de alumnos nacidos en la década de los sesenta. Nos encontramos, pues, en esas fechas, con miles de docentes interinos, los antiguos PNNs (profesores no numerarios), que ejercían una gran presión política y sindical para estabilizar su situación.

Para solucionar esta problemática se aprobó, mediante el Real Decreto-Ley 22/1977 ${ }^{7}$, una reforma de la legislación de la Administración Civil del Estado que permitió, durante un periodo transitorio, una reserva de plazas exclusivamente para funcionarios interinos. Desde entonces las convocatorias para el ingreso en los cuerpos docentes establecieron, junto a un turno de libre acceso, un concursooposición restringido a quienes estuviesen prestando servicios como interinos. Esta situación, a través de la cual acudieron la función docente más de 100.000 interinos, se prolongó hasta el año 1984 en que se aprobó la ley 30/1984 de Medidas para la Reforma de la Función Pública que puso fin a esta situación.

Lo curioso es que la constitucionalidad de las pruebas restringidas no fue objeto de control por el Tribunal Constitucional hasta la STC 27/1991, de 14 de febrero, por lo que estuvieron plenamente operativas durante ocho años sin que nadie impugnara este sistema de acceso ante el Tribunal Constitucional, por vulnerar el art. 23.2 CE.

A este respecto, el Alto Tribunal determina que las llamadas pruebas restringidas «han de considerarse como un procedimiento pros-

7 Disposición adicional Quinta, dos: «Durante un plazo máximo de cinco años, en las convocatorias a que se refiere el número anterior, podrá reservarse un porcentaje determinado de las vacantes existentes para su provisión entre funcionarios interinos y personal contratado de colaboración temporal que presten sus servicios a la entrada en vigor del presente Real Decreto-Ley y continúen prestándolos al publicarse la correspondiente convocatoria.» 
crito por el art. $23.2 \mathrm{CE} »^{8}$, si bien no cabe excluir que, en determinados casos excepcionales, su utilización pueda considerarse como razonable, proporcionada y no arbitraria, siempre que se acuda a ese procedimiento «una sola vez» para "para resolver una situación singular derivada de un proceso único e irrepetible» (en ese caso la creación de una nueva forma de organización de las Administraciones Públicas a nivel autonómico) y que se articule a través de una Ley9

Sin embargo hay que advertir que la utilización de pruebas restringidas en el acceso a la función docente ha pervivido en algunos casos excepcionales, bajo fórmulas camufladas. Una de estas prácticas consiste en convertir empleados públicos laborales en funcionarios de carrera, mediante procedimientos restringidos habilitados al efecto. Este procedimiento, llamado funcionarización, fue instaurado por primera vez por la Ley 31/1990, de 27 de diciembre, de Presupuestos del Estado para el año 1991, cuyo artículo 37 permitió establecer un turno especial de acceso a los puestos de trabajo para los contratados laborales fijos que estuvieren desempeñando puestos de trabajo correspondientes a funcionarios de carrera ${ }^{10}$. Amparadas por dicha legislación, las Comunidades Autónomas establecieron, en sus respectivas leyes de función pública, procesos voluntarios de funcionarización a través de distintos procedimientos, algunos tan laxos como la simple superación de un curso de formación ${ }^{11}$.

Este procedimiento de funcionarización fue avalado por la STS

8 STC 27/1991, de 14 de febrero, F.J. $5^{\circ}$

9 Ver la STC 16/1998, de 26 de enero. F.J. $5^{\circ}$. 1991

${ }^{10}$ Ley 31/1990, de 27 de diciembre, de Presupuestos Generales del Estado para

Art. 37 Funcionarización del personal laboral

Uno. Las pruebas selectivas de acceso a los Cuerpos, Escalas o Especialidades. a que se adscriban las plazas correspondientes a puestos servidos por personal laboral y clasificados como propios de personal funcionario, podrán incluir un turno que se denominará de «Plazas afectadas por el artículo 15 de la Ley de Medidas», en el que podrá participar el personal afectado por lo establecido en la disposición transitoria 15 de la Ley de Medidas para la Reforma de la Función Pública, adicionada por laLey 23/1988, de 28 de julio, en los artículos 39 y 33 de las Leyes de Presupuestos Generales del Estado para 1989 y 1990, respectivamente, y en el artículo 32 de la presente Ley.

Dos. El personal laboral que supere las pruebas selectivas de acceso quedará destinado en el puesto de trabajo de personal funcionario en que su puesto se haya reconvertido y deberá permanecer en el mismo durante un plazo mínimo de dos años, conforme a las previsiones contenidas en el artículo 20.uno f), de la Ley 30/1984, de 2 de agosto.

${ }_{11}$ Véase lo previsto en la disposición adicional octava de la Ley de Función Pública Asturiana, aprobada por la Ley 4/1996, de 13 de diciembre. 
5095/1996, de 20 de junio de 1996, al entender que «el art. 37.1 de la Ley precitada (de presupuestos) cumple con la doctrina del Tribunal Constitucional (STC 27/1991, de 14 de febrero) en relación con los principios de igualdad, mérito y capacidad en el acceso a la Función Pública». El Tribunal Supremo entiende que este proceso de funcionarización constituye una «situación excepcional» en la que concurre un fin legítimo de «dar solución a un colectivo singular: el de determinado personal laboral fijo, caracterizado por venir desempeñando puestos de trabajo, reservados a funcionarios» y de esta manera posibilitar «que la naturaleza jurídica de su relación de servicios con la Administración, se adecue a la naturaleza funcionarial del puesto que sirven». Además el Tribunal Supremo justifica el carácter restringido de las pruebas en la estabilidad en el empleo de este personal laboral fijo pues «si las pruebas se hubieran convocado en turno libre, pues entonces hubiera sido posible que accediera desde fuera de la Administración un nuevo funcionario para ocupar una plaza que ya tenía titular, con la consiguiente extralimitación de límites presupuestarios para una misma plaza.»

Como ya hemos apuntado estos procesos de funcionarización han estado presentes en el acceso a la función docente en distintos momentos. Prueba de ello es que la actual Ley Orgánica 2/2006 de Educación ${ }^{12}$ contempla en su disposición transitoria quinta, un procedimiento excepcional durante tres años, para la funcionarización del personal laboral fijo en centros docentes, mediante la realización de pruebas específicas.

Ahora bien estos sistemas excepcionales de acceso pueden adolecer de vicios de inconstitucionalidad sino se llevan a cabo con un escrupuloso respeto a los principios constitucionales de igualdad, mé-

${ }^{12}$ Disposición transitoria quinta. Personal laboral fijo de centros dependientes de Administraciones no autonómicas.

1. Cuando se hayan incorporado, con anterioridad a la entrada en vigor de la presente Ley, o se incorporen durante los tres primeros años de su aplicación, centros previamente dependientes de cualquier Administración Pública a las redes de centros docentes dependientes de las Administraciones educativas, el personal laboral que fuera fijo en el momento de la integración y realice funciones docentes en dichos centros, podrá acceder a los cuerpos docentes regulados en esta Ley, previa superación de las correspondientes pruebas selectivas convocadas a tal efecto por los respectivos Gobiernos de las Comunidades Autónomas. Dichas pruebas deberán garantizar, en todo caso, los principios constitucionales de igualdad, mérito y capacidad, en la forma que determinen los Parlamentos autonómicos, debiendo respetarse, en todo caso, lo establecido en la normativa básica del Estado.

2. Los procedimientos de ingreso a que hace referencia esta disposición sólo serán de aplicación en el plazo de tres años. 
rito y capacidad. Un ejemplo de ello nos lo ofrece la STC 31/2006, de 1 de febrero, en la que se conoce del recurso de inconstitucionalidad contra el art. 10 de la Ley del País Vasco 16/1997, que modifica la Ley de Función Pública Vasca. En dicho precepto se establecía que «el personal docente que tenga la condición de laboral fijo, y esté adscrito a plazas incluidas en las vigentes relaciones de puestos de trabajo docentes del Departamento de Educación, Universidades e Investigación podrá acceder a la condición de funcionario de carrera docente en el Cuerpo correspondiente al nivel de la plaza a la que está adscrito, aun careciendo de la específica titulación para el acceso a dicho cuerpo, mediante pruebas selectivas restringidas que, con carácter excepcional, podrán ser convocadas por la Administración Educativa». El Tribunal Constitucional, si bien declara inconstitucional el precepto por desbordar la normativa estatal básica en materia de acceso a la función pública, realiza otras consideraciones que entendemos importantes para valorar la constitucionalidad de estos procesos. Advierte atinadamente el Tribunal, en su fundamento jurídico $5^{\circ}$, que en este caso "no estamos ante una mera medida de promoción del personal funcionario, sino de la conversión del personal laboral contratado por personas y entidades jurídico-privados, asumido después, a través de una relación laboral, por la Administración Autonómica y que pretende integrarse por esta vía en la función pública docente sin contar con la titulación exigida por la normativa estatal básica». Y es que, en el caso que nos ocupa, nos encontramos con personal que pertenecía a centros privados de enseñanza que, tras la integración de las ikastolas en la red pública de centros pasaron a tener una relación laboral de carácter fijo con la Administración. Por ello es necesario, a nuestro juicio, distinguir, entre procesos de funcionarización de personal laboral fijo que haya adquirido dicha condición en virtud de la superación de procedimientos selectivos de oposición o concursooposición, con escrúpulo respeto a los principios constitucionales tantas veces mencionados, de aquellos otros que han accedido a esta situación por cualquier otra circunstancia ajena a los principios y normas que rigen el acceso a la función pública. En el primero de los caso podríamos entender que estamos ante procesos de promoción profesional, también llamada promoción cruzada, amparados por el Tribunal Constitucional en la STC 50/1986, de 23 de abril ${ }^{13}$. En el segundo de los supuestos nos hallamos, sin duda, con una vulneración

13 STC 50/1986, de 23 de abril F.J. 4: «No se trata aquí, en efecto, de una convocatoria para el ingreso en la función pública (la que simultáneamente se hizo con esta finalidad estaba abierta por igual a funcionarios y no funcionarios), sino de una promoción entre funcionarios para el acceso a las plazas de oficial, aunque a través del 
encubierta de los principios constitucionales de igualdad, mérito y capacidad que deben presidir el acceso a todas las funciones públicas ${ }^{14}$.

\section{OTROS SISTEMAS EXCEPCIONALES DE ACCESO: LA ANTIGÜEDAD COMO MÉRITO PREFERENTE}

Un sistema frecuentemente utilizado por nuestras Administraciones Públicas para posibilitar la estabilización de los funcionarios interinos, ha sido la convocatoria de concursos-oposición que, si bien eran abiertos a la participación de todos los ciudadanos que reunieran los requisitos generales, colocaban a los interinos en una situación de ventaja al valorar de manera preferente como mérito, los servicios prestados a la Administración.

De esta cuestión se ocupó la importante STC 67/1989, de 18 de abril, al resolver un recurso de amparo en una convocatoria de pruebas selectivas para el ingreso en el Cuerpo de Titulados Superiores de la Administración de Extremadura. Se planteaba en dicha sentencia si era constitucionalmente admisible que, en un concurso-oposición libre, se valorase únicamente como mérito los servicios efectivos prestados por el personal interino y contratado, en los términos previstos en la Disposición Transitoria segunda de la Ley 2/1986, de 23 de mayo de la Función Pública de Extremadura ${ }^{15}$.

Según reconoce el Tribunal Constitucional en la STC 67/1989, nada se opone a que se reconozca como mérito los servicios prestados a la Administración, pues no son ajenos al concepto de mérito y capacidad ya que «pueden reflejar la aptitud o capacidad para desa-

sistema selectivo del concurso-oposición, lo que no resulta contrario a la Constitución sino acorde con ella, dado el mandato constitucional de favorecer la promoción mediante el trabajo (art. 35.1).»

${ }^{14}$ STC 31/2006, de 1 de febrero, F.J. 5: «El desconocimiento de los principios de mérito y capacidad previstos para el acceso a la función pública en la normativa impugnada «menoscaba la capacidad como requisito absoluto para el desempeño de cada puesto de trabajo concreto y niega el mérito como elemento relativo de comparación y preferencia para el acceso o nombramiento» (STC 388/1993, de 23 de diciembre, F. 2), en la medida en que rompe el régimen general aplicable en todo el territorio nacional, que, indudablemente, está en el fundamento de lo básico.»

15 Disposición Transitoria segunda:

«1. El personal interino existente al entrar en vigor esta Ley y seleccionado a través de pruebas selectivas convocadas por la Comunidad Autónoma de Extremadura, se someterá a las pruebas selectivas que se estimen necesarias por concursooposición libre, para su ingreso en la función pública, si las consignaciones presupuestarias lo permiten. En ellas se valorarán los servicios efectivos prestados, teniendo en cuenta de forma estricta los principios de mérito y capacidad.» 
rrollar una función o empleo público y, suponer además, en ese desempeño, unos méritos que pueden ser reconocidos y valorados.» Además el Tribunal estima que la valoración como mérito de la antigüedad «no constituye, ni directa ni indirectamente una referencia individualizada, singular específica y concreta.» Ahora bien, se plantea si es constitucionalmente lícito valorar como único mérito la antigüedad, excluyendo cualquier otro elemento de capacidad y valía personal y profesional de los aspirantes. El Tribunal, si bien reconoce que esta medida «efectivamente establece una desigualdad», "no puede estimarse como una medida desproporcionada, arbitraria o irrazonable» en base a la consabida finalidad de consolidar la puesta en marcha de una nueva Administración Autonómica y, por lo tanto, con fundamento en un interés público legítimo.

Problema distinto es el de si la ponderación de ese único mérito valorable es tan desproporcionada e irracional que puede desconocer el derecho a la igualdad. En ese sentido, el Tribunal reconoce que, dentro de la razonable libertad de la Administración en la fijación de los méritos y en su valoración, cabe comprobar por el Tribunal si dicha ponderación «es manifiestamente irracional, no responde a criterio admisible de general aceptación, y supone prácticamente la exclusión de otros, en este caso los que concurren desde fuera de la Administración.» En el caso que nos ocupa, los servicios prestados podrían llegar a suponer hasta un máximo de un $45 \%$ de la puntuación alcanzable en la fase de oposición. El Tribunal estima que esta valoración del mérito de tiempo de servicios está «en el límite de lo tolerable», pues aunque supone una ventaja para los que acrediten este mérito, «no excluye por entero de la competición a quienes carecen de él», pese a que les imponga para situarse a igual nivel de puntuación que los interinos un nivel de conocimientos superior, "pero sin que ello signifique un obstáculo que impida al acceso a la función pública de quienes no prestaron servicios a la Administración anteriormente».

Pese a todo lo anterior, la STC 67/1989 acuerda finalmente estimar el recurso de amparo declarando la nulidad de la convocatoria para el ingreso en la función pública extremeña. La clave de la estimación del recurso se halla en la posibilidad que contemplaba la convocatoria, de utilizar los puntos obtenidos en la fase de concurso para alcanzar las puntuaciones mínimas exigidas en los ejercicios de la fase de oposición ${ }^{16}$. Este sistema, llamado de la mochila, es el determinante de la declaración de inconstitucionalidad, pues como

${ }^{16}$ Base 4.1: «Los puntos así obtenidos en la fase de concurso, tanto en turno libre como en promoción, se aplicarán, si fuera necesario, a la puntuación obtenida en 
señala el Alto Tribunal, «esta diferencia sensible de niveles de exigencia supone que los aspirantes de fuera vean reducida al mínimo su posibilidad de acceso a la función pública, exigiéndoseles un nivel de conocimientos elevado, mientras que los opositores, que ya prestan servicios en la Administración Autonómica, pueden aprobar los correspondientes ejercicios con notas muy inferiores y que no garantizan la suficiencia de sus conocimientos.»

Por ello, el Tribunal considera que el sistema de mochila restringe la competencia externa de la misma manera que las pruebas restringidas y supone una desigualdad de trato arbitraria e incompatible con los principios de mérito y capacidad.

Resumiendo la doctrina del Tribunal Constitucional sobre esta cuestión, emanada de la trascendental STC 67/1989, «el problema de la igualdad no se suscita por la consideración como mérito de los servicios prestados, sino por el hecho de constituir un requisito necesario para poder participar en el concurso -pruebas restringidas-, por la relevancia cuantitativa que pueda atribuir la convocatoria a dichos servicios o por operar doblemente, en distintas fases del procedimiento de selección ${ }^{17}$. Todo ello desde la consideración del Alto Tribunal de que otorgar determinados beneficios o ventajas a los funcionarios interinos es plenamente constitucional, si tiene por finalidad consolidar la situación del empleo precario dentro de procesos excepcionales de creación de las Administraciones Autonómicas.

Estos procesos selectivos ventajosos para los funcionarios interinos también han tenido cabida en el acceso a la función docente. Así, la disposición transitoria quinta de la LOGSE, apartado 2, estableció que «las tres primeras convocatorias de ingreso en la función pública docente, que se produzcan después de la entrada en vigor de la presente Ley, se realizarán conforme a un sistema de selección en el que se valoren los conocimientos sobre los contenidos curriculares que deberán impartir los candidatos seleccionados y su dominio de los recursos didácticos y pedagógicos, así como los méritos académicos. Entre éstos «tendrán una valoración preferente los servicios prestados en la enseñanza pública». Para la selección de los aspirantes se tendrán en cuenta la valoración ponderada y global de ambos apartados.

cada ejercicio de la fase de oposición, de forma tal que, sumados a los obtenidos, la calificación de ésta alcance en su caso la puntuación mínima establecida para superar el correspondiente ejercicio. Dicha aplicación no será posible cuando en un ejercicio de la fase de oposición la calificación obtenida sea inferior a 2,50 puntos.»

17 STC 83/2000, de 27 de marzo F.J. $4^{\circ}$. 
La constitucionalidad de esta disposición fue ratificada por la STC 185/1994, de 20 de junio, en la que el Tribunal, si bien reconoce que no estamos ante «un proceso irrepetible por crearse una nueva Administración», justifica esa desigualdad de trato en la importante reforma educativa que supuso la LOGSE que «puede requerir que se adopten medidas de carácter excepcional y transitorio, entre ellas, las orientadas a la adecuada cualificación del profesorado en los centros escolares.» Entre estas medidas el Tribunal admite un «sistema de ingreso en el que se favorece el acceso de aquellos aspirantes que previamente hubiesen sido contratados», como medio para resolver el problema de interinidad en el desempeño de las plazas existentes en la Administraciones educativas.

«El trato de favor concedido a los aspirantes que con anterioridad hubiesen desempeñado tareas docentes como funcionarios interinos posee un carácter excepcional y deriva de una circunstancia vinculada a una finalidad constitucionalmente legítima, como es la de normalizar la situación del personal al servicio de las Administraciones educativas y mejorar su cualificación. Por eso si la LOGSE entraña la reforma del sistema educativo en su conjunto y los poderes públicos han de prestar una atención prioritaria al conjunto de factores que favorecen la calidad y mejora de la enseñanza, entre otros se cuenta, obvio es, la adecuada cualificación del profesorado, incluido el que ha venido desempeñando sus funciones con carácter interino» (STC 185/1994, de 20 de junio F.J. $4^{\circ}$ ).

Esta sentencia supone un nuevo planteamiento sobre la doctrina que el Alto Tribunal venía manteniendo sobre este tipo de pruebas. Por un lado se supera la exigencia de una única convocatoria, derivada de un proceso único e irrepetible, pues la disposición transitoria objeto de la sentencia permite la realización de este sistema excepcional durante tres convocatorias. Pero además la sentencia legitima la práctica de estos procesos selectivos excepcionales, no sólo por la creación de nuevas Administraciones autonómicas, sino también por la existencia de reformas legislativas en sectores que, como el educativo, merezcan por su importancia una consideración singular.

Ahora bien, los procesos excepcionales favorecedores de los funcionarios interinos no concluyeron con la LOGSE. La todavía reciente Ley Orgánica 2/2006, de 3 de mayo, de Educación, establece en su disposición transitoria decimoséptima un nuevo sistema excepcional de acceso durante cuatro años, so pretexto de reducir el porcentaje de profesores internos en los centros educativos ${ }^{18}$. Así en el

${ }_{18}$ Disposición transitoria decimoséptima. Acceso a la función pública docente.

1. El Ministerio de Educación y Ciencia propondrá a las Administraciones 
apartado 2 de la mencionada disposición transitoria se establece una fórmula que nos recuerda a las vistas en otras épocas y situaciones:

«Durante los años de implantación de la presente Ley, el acceso a la función pública docente se realizará mediante un procedimiento selectivo en el que, en la fase de concurso se valorarán la formación académica y, de forma preferente, la experiencia docente previa en los centros públicos de la misma etapa educativa, hasta los límites legales permitidos...»

El problema radica en que la presunta excepcionalidad de las situaciones que amparan estos sistemas ha venido a convertirse más bien en regla general. Como hemos visto, entre pruebas restringidas y otros sistemas favorecedores del acceso de los funcionarios interinos, podemos afirmar que, cumplidos ya más de treinta años desde la aprobación del texto constitucional, durante casi la mitad del tiempo transcurrido los sistemas de acceso a la función docente han sido regulados por procedimientos excepcionales en detrimento de los principios constitucionales de igualdad, mérito y capacidad.

\section{DEVALUACIÓN DEL PRINCIPIO CONSTITUCIONAL DE CAPACIDAD MEDIANTE LA DESNATURALIZACIÓN DE LA FASE DE OPOSICIÓN}

Hemos visto a lo largo de este trabajo como el Tribunal Constitucional ha amparado la constitucionalidad de distintos tipos de pruebas de acceso que otorgan ventajas a los funcionarios interinos con fundamento, en unos casos a la creación de una nueva Administración Autonómica, y, en otros, como en el sector docente, en la aprobación de una nueva Ley de Educación que supuso una importante reforma del sistema de enseñanzas en España. Ahora bien, el propio Tribunal ha advertido que ello no es obstáculo para fiscalizar la constitucionalidad de las disposiciones reglamentarias que regulan estos procesos pues, si bien se admiten ciertas ventajas en relación al personal temporal, ello no supone un cheque en blanco para la Administración que anule y deje sin contenido el art. $23.2 \mathrm{CE}^{19}$. Por ello el

educativas, a través de la Conferencia Sectorial de Educación, la adopción de medidas que permitan la reducción del porcentaje de profesores interinos en los centros educativos, de manera que en el plazo de cuatro años, desde la aprobación de la presente Ley, no se sobrepasen los límites máximos establecidos de forma general para la función pública.

19 STC 185/1994, de 20 de junio, F.J. 5: «Cuestión distinta es determinar si las disposiciones reglamentarias que lo desarrollan (la disposición transitoria quinta, 3 de la 
Tribunal Constitucional ha entrado a analizar, en diversas sentencias, los decretos que regulan los sistemas de acceso e incluso las concretas convocatorias de pruebas selectivas.

Uno de los sistemas más utilizados por la Administración Educativa para favorecer el acceso de los funcionarios interinos, consiste en desnaturalizar de diversas maneras la fase de oposición, de tal suerte que sea la fase de concurso, en la que el peso de la antigüedad tiene un peso determinante, la que decida la suerte final del proceso selectivo. Con la expresión desnaturalizar queremos referirnos a diversos mecanismos diseñados con el oculto fin de facilitar la superación de la oposición, despojándola de esta manera de su sentido primigenio como prueba selectiva, y convirtiéndola incluso en un mero trámite.

Un ejemplo palmario de ello nos lo ofrece el Real Decreto 574/1991, del Ministerio de Educación y Ciencia, que reguló transitoriamente el ingreso en los cuerpos de funcionarios docentes, tal y como previó la LOGSE. Sin ánimo de desentrañar todos los detalles del procedimiento diseñado, pues sería muy prolijo, reseñaremos los aspectos esenciales del sistema de acceso que han sido objeto de análisis jurisprudencial.

Por un lado, la valoración de los conocimientos sobre los contenidos curriculares propios de la especialidad a la que optaban los candidatos y su dominio de los recursos didácticos y pedagógicos, se llevaba a cabo a través de la exposición oral por el aspirante ante el Tribunal de un tema de la especialidad correspondiente y de su planteamiento didáctico. La exposición era seguida de un debate con el Tribunal. Los Tribunales valoraban esta fase del proceso selectivo entre cero y diez puntos. Respecto a la fase de concurso tenían la consideración de méritos, además de la experiencia previa, las calificaciones contenidas en el expediente académico correspondiente al título exigido para el ingreso, los cursos de formación y perfeccionamiento superados, así como los otros posibles méritos relacionados con el expediente académico que se determinen en la convocatoria. Ahora bien, conforme a este sistema superaban la fase de oposición quienes obtuvieran al menos cinco puntos agregando a la nota de la prueba de conocimientos, la puntuación del resto de los méritos, excluida la experiencia previa, es decir cursos de perfeccionamiento y expediente académico. Por tanto, con un sistema como el descrito, un aspirante que hubiere obtenido en la prueba de conocimiento una nota inferior a un cinco, podría superar la fase de oposición aportando la puntuación procedente de cursos de perfeccionamiento. 
Este sistema fue declarado constitucional por diversas senten$\operatorname{cias}^{20}$ del Alto Tribunal que, a nuestro juicio, no dieron respuesta a todos los interrogantes que plantean sistemas de acceso de esta naturaleza en relación a su compatibilidad con los principios constitucionales de igualdad, mérito y capacidad. En primer lugar el Tribunal se limita a constatar que no estamos ni ante pruebas restringidas $^{21}$, ni ante un sistema de mochila ${ }^{22}$, ambos proscritos por la doctrina del propio Tribunal. Asimismo la sentencia verifica que la valoración de la experiencia docente se halla dentro de los límites tolerables fijados por la propia doctrina del propio Tribunal ${ }^{23}$. Por todo ello, el Tribunal, sin entrar en mayores profundidades, estima que todos «los aspirantes son tratados por igual», por lo que el sistema es plenamente constitucional. Hay que decir que las SSTC 185/1994 y 11/1996 contaron con el voto particular del Magistrado don José Gabaldón López. Según este Magistrado, en un sistema como el analizado la puntuación otorgada en concepto de experiencia previa «tendrá finalmente un peso decisivo hasta el punto de colocarles (a los interinos) en una situación preferente con muchas más posibilidades de obtener plaza» ${ }^{24}$.

LOGSE) y, más concretamente, la Orden de convocatoria objeto de recurso, incrementan esa desigualdad más allá de los límites constitucionalmente tolerables».

${ }^{20}$ SSTC 185/1994, de 20 de junio, 238/1994, de 20 de julio, 11/1996, de 29 de enero y $83 / 2000$, de 27 de marzo.

21 STC 83/2000, de 27 de marzo, F.J. 4: «No nos encontramos ante pruebas restringidas, ya que en primer lugar, a las mismas podían presentarse aspirantes que nunca hubieran desempeñado puestos docentes en la Administración educativa.

22 STC 185/1994, de 20 de junio, F.J. 6º: «Es evidente que los servicios prestados no puntúan doblemente, en dos momentos o fases distintas del proceso de selección, sino que se computan separadamente dentro de esa valoración ponderada y global».

${ }^{23}$ STC 185/1994, de 20 de junio, F.J. 6: «El máximo de seis puntos que las Comisiones pueden otorgar a los profesores interinos por la previa experiencia docente representa el 31,57 por ciento del total de puntos que pueden obtenerse en los tres cómputos que integran el procedimiento de selección... por lo que puede considerarse que se sitúa dentro del límite de lo tolerable (STC 67/1989, F,J, 4)».

${ }_{24}$ «Los 6 puntos de máxima que pueden alcanzarse por servicios prestado, aunque sólo signifiquen algo menos de la tercera parte del total posible por todos los conceptos, son sin embargo un 45 por ciento de la suma de todos los demás conceptos valorables. De estos últimos, el de mayor significación (10 puntos) es el que valora los conocimientos curriculares que, sin embargo, en el cómputo final tendrá un peso inferior al de los 6 puntos por servicios prestados, puesto que obtener nota máxima o aproximada en el examen de conocimientos será lógicamente excepcional y propio de pocos aspirantes, en tanto que acreditar el máximo por servicios constituirá un resultado no sólo frecuente sino incluso general, dado que pueden obtener hasta 1,5 puntos por año de servicios y la antigüedad de sus nombramientos prácticamente pronostica unos máximos generalizados. Los no interinos quedarán necesariamente en desventaja pues las plazas se otorgan finalmente por orden de puntuación total.» Voto particular del Magistrado José Gabaldón López a la STC 185/1994, de 20 de junio. 
Con una mayor profundidad estudió el Tribunal Supremo la constitucionalidad del sistema de acceso regulado por el RD 574/1991, especialmente en la STS de 9 de diciembre de 1997, con ocasión de un recurso de casación interpuesto por la Generalidad Valenciana contra una sentencia del Tribunal Superior de Justicia de Valencia. La sentencia de la sala de lo contenciosos del Tribunal Superior de Justicia considera que esa normativa de acceso vulneraba los principios de igualdad, mérito y capacidad que se consagran en los artículos 23.2 y 103.3 $\mathrm{CE}^{25}$. Para llegar a esta conclusión la Sala argumenta que no pueden entenderse garantizados los principios de mérito y capacidad si no se confiere a la prueba de conocimientos carácter eliminatorio. Según la Sala «no puede sostenerse como una peculiaridad la posibilidad de añadir méritos a aquella valoración, ya que supone la posibilidad de suplir la inexistencia actual de conocimientos ${ }^{26}$. Sobre estas bases la sentencia razona la necesaria existencia de una fase de oposición con carácter eliminatorio, para los que no superen en ella cinco puntos; y de un posterior concurso de méritos, entre los que superen la primera, en cuyo concurso se sumarán los correspondientes méritos, declarando el Tribunal no acumulables en la fase de oposición los méritos del concurso, tal y como establecía el RD 574/1991, hecho que la sentencia considera contrario a los principios constitucionales referidos.

Sin embargo el Tribunal Supremo rechaza estas argumentaciones y avala la constitucionalidad del sistema de acceso que estamos analizando. Según la referida STS de 9 de diciembre de 1997, la primera fase «no es una oposición al modo de las que se realizan para el ingreso en los grandes cuerpos funcionariales» sino una "prueba mixta» en que los conocimientos se demuestran mediante los que se acreditan oralmente, y el añadido de otros previamente adquiridos a través del expediente académico o cursos de formación permanente. Mediante este curioso razonamiento el Tribunal Supremo llega a la conclusión de que «no cabe decir que no se respetan los principios de mérito y capacidad del art. 103.3 CE, cuando para medir los conocimientos sobre los contenidos cuniculares que deberán impartir los

${ }^{25}$ Ver sentencia dictada en 24 de diciembre de 1993 por la Sala de lo Contenciosoadministrativo del Tribunal Superior de Justicia de la Comunidad Valenciana, especialmente los fundamentos de derecho $4^{\circ}$ y $5^{\circ}$.

${ }_{26}$ Ciertamente con el sistema diseñado por el RD 574/1991 un aspirante que hubiera sido calificado con un 2 en la prueba oral sobre un tema de su especialidad (por ejemplo matemáticas), aprobaría la prueba de conocimientos mediante la incorporación de 3 puntos provenientes de cursos de perfeccionamiento, como por ejemplo los impartidos por los sindicatos. 
candidatos, se utilizan méritos académicos preexistentes propios de la fase de concurso, o impropios para esa finalidad, ya que los previstos en el caso concernientes al expediente académico, títulos o cursos de perfeccionamiento, sirven también para acreditar la posesión de conocimientos.» (Fundamento de derecho cuarto).

Esta cuestión nos remite a la cuestión relativa al contenido y alcance de los principios constitucionales de mérito y capacidad, pues, como el propio Tribunal Constitucional señaló, estamos ante conceptos indeterminados ${ }^{27}$. La corriente doctrinal dominante ${ }^{28}$ vincula el principio de capacidad con el sistema selectivo conocido como oposición, es decir, con la celebración de una o más pruebas para determinar la capacidad y la aptitud de los aspirantes, y asocia el mérito con el concurso, consistente en la comprobación y calificación de los méritos de los aspirantes. Por su parte la jurisprudencia, si bien no es del todo clara a la hora de precisar el contenido de estos principios constitucionales, en algunos casos aporta sentencias que coinciden con el anterior planteamiento. Así la sentencia del Tribunal Supremo, de 3 de noviembre de 1986, establece que los elementos determinantes de la capacidad son aquellos que se acreditan en pruebas teóricas o prácticas que realizan los aspirantes sobre un temario predeterminado, destinadas a verificar los conocimientos y la capacidad de los aspirantes en relación a la función pública a la que se accede. Por su parte, el mérito abarcaría aquellos elementos que, al margen de todo tipo de pruebas, hacen referencia a la cualificación obtenida por los aspirantes a lo largo de su trayectoria personal y profesional, tales como el trabajo desarrollado, la formación de perfeccionamiento recibida, la antigüedad, las publicaciones, etc.

Desde este planteamiento cabe preguntarse si es acorde con los principios constitucionales estudiados un sistema de acceso que desnaturalice de tal modo la fase de oposición que esta apenas carezca de sentido y sea más un mero trámite que una verdadera prueba que acredite los conocimientos necesarios para el acceso a una función pública. ¿Se cumple el principio de capacidad cuando un aspirante a profesor de matemáticas accede a la función pública habiendo obtenido una calificación de dos sobre diez en la prueba de conocimientos de su especialidad?

27 STC 50/1986, de 23 de abril, F.J. 4: «...no puede negarse un amplio margen, tanto al legislador como a la Administración, para dotar de contenido concreto en cada caso a conceptos indeterminados como son los de mérito y capacidad.»

${ }_{28}$ Ver el apartado dedicado en este trabajo a los principios de mérito y capacidad. 
Resulta evidente que sistemas de esta naturaleza están diseñados con el no disimulado propósito de favorecer el acceso de los funcionarios interinos. Una fase de oposición descafeinada junto a una valoración más que generosa de los servicios prestados, coloca a los funcionarios interinos en una situación de ventaja casi insalvable para quien no tenga ninguna antigüedad. El Tribunal Constitucional estima que no se vulnera la igualdad en el acceso si «no excluye por entero de la competición» a quienes carecen de antigüedad ${ }^{29}$. Esto, si bien es cierto desde un plano meramente teórico, se convierte en la práctica en un obstáculo insalvable para quienes carezcan de experiencia, no siendo infrecuentes situaciones en que aspirantes con un diez de calificación en la fase de oposición no acceden a la función pública.

Como veremos en el siguiente epígrafe de este trabajo, hay muchos más sistemas, además del analizado en este caso, para desnaturalizar la fase de oposición en beneficio de los funcionarios interinos. Cabe preguntarse hasta dónde es posible llegar con estas prácticas y cual es el contenido y alcance real de los principios constitucionales de mérito y capacidad, inherentes al derecho a la igualdad en el acceso a la función pública.

\section{ANÁLISIS DEL SISTEMA TRANSITORIO DE ACCESO A LA FUNCIÓN DOCENTE DE LA ACTUAL LEY ORGÁNICA DE EDUCACIÓN}

1. De nuevo un sistema excepcional de acceso a la función docente.

Dedicaremos el último apartado de este trabajo a realizar un estudio del sistema transitorio de ingreso a la función pública docente, que ha venido operando desde el año 2006 en que se aprobó la actual Ley de Educación, hasta el año 2011. Este sistema es particularmente interesante pues reúne, a nuestro juicio, muchas de las cuestiones que han sido abordadas a lo largo de este trabajo y algunas novedades que merecen ser analizadas.

En primer lugar hay que decir que estamos de nuevo ante un sistema excepcional de acceso regulado en la disposición transitoria decimoséptima de la LOE. La ley justifica el establecimiento de un sistema excepcional, distinto al ordinario previsto en la disposición adicional duodécima, en la necesidad de reducir el porcentaje de

29 Véase STC 67/1989, de 18 de abril. 
profesores interinos en los centros educativos ${ }^{30}$. A tal efecto se diseña un procedimiento cuyas líneas básicas son las siguientes:

«Durante los años de implantación de la presente Ley (cinco años), el acceso a la función pública docente se realizará mediante un procedimiento selectivo en el que, en la fase de concurso se valorarán la formación académica y, de forma preferente, la experiencia docente previa en los centros públicos de la misma etapa educativa, hasta los límites legales permitidos. La fase de oposición, que tendrá una sola prueba, versará sobre los contenidos de la especialidad que corresponda, la aptitud pedagógica y el dominio de las técnicas necesarias para el ejercicio de la docencia.» (Disposición transitoria decimoséptima apartado 2 de la LOE).

El establecimiento de sistemas que favorecen el acceso de los funcionarios interinos ha sido aceptado por el Tribunal Constitucional, en diversas sentencias, si bien como hemos visto, con ciertos condicionantes. Recapitulemos brevemente los antecedentes constitucionales. La STC 67/1989, de 18 de abril, si bien reconoce que en la disposición transitoria segunda de la Ley 2/1987 de la Función Pública de Extremadura «se conceden algunas facilidades o beneficios» a los interinos, los justifica por las «especiales circunstancias creadas por la puesta en marcha de la Administración Autonómica y la necesidad de contar inmediatamente con personal propio» ${ }^{31}$. Más adelante la STC 27/1991, de 14 de febrero, que resuelve una cuestión de inconstitucionalidad sobre la disposición transitoria sexta, apartado $4^{\circ}$ de la Ley 30/1984, se pronunció sobre las pruebas restringidas para funcionarios interinos. La sentencia entiende que la diferencia de trato establecida en la Ley a favor de unos y en perjuicio de otros puede considerarse como razonable, proporcionada y no arbitraria a los efectos de la desigualdad de trato que establece, "siempre que dicha diferenciación se demuestre como un medio excepcional y adecuado para resolver una situación también excepcional y con el objeto de alcanzar una finalidad constitucionalmente legítima, entre las que se integra también la eficacia de la Administración Pública». En el ámbito docente, la STC 185/1994, de 20 de ju-

${ }^{30}$ Disposición transitoria decimoséptima. Acceso a la función pública docente:

1. «El Ministerio de Educación y Ciencia propondrá a las Administraciones educativas, a través de la Conferencia Sectorial de Educación, la adopción de medidas que permitan la reducción del porcentaje de profesores interinos en los centros educativos, de manera que en el plazo de cuatro años, desde la aprobación de la presente Ley, no se sobrepasen los límites máximos establecidos de forma general para la función pública.»

31 A pesar de ello la STC 67/1989 declaró inconstitucional tal precepto por incluir un sistema de mochila que el Altor Tribunal consideró contrario al art. 23.2 CE. 
nio, analizada en un apartado anterior, manifiesta que «el trato de favor concedido a los aspirantes que con anterioridad hubiesen desempeñado tareas docentes como funcionarios interinos posee un carácter excepcional y deriva de una circunstancia vinculada a una finalidad constitucionalmente legítima, como es la de normalizar la situación del personal de las Administraciones educativas y mejorar su cualificación.»

Como vemos la doctrina constitucional ha venido imponiendo dos condiciones para avalar sistemas de acceso que establezcan ventajas para los interinos. Por un lado que se trate de un sistema excepcional para resolver una situación también excepcional. En segundo lugar que se persiga una finalidad constitucionalmente legítima. El sistema transitorio regulado en la LOE persigue una finalidad que el Tribunal ha venido considerando legítima, cual es la consolidar el empleo público temporal ${ }^{32}$. Lo que ciertamente plantea dudas más que justificadas es que se trate de un remedio excepcional para una situación excepcional. Hemos visto que el Alto Tribunal ya avaló un sistema excepcional de consolidación del empleo temporal establecido en la LOGSE. Como señala la mencionada STC $185 / 1994^{33}$, la LOGSE supuso una reforma global y en profundidad del sistema educativo, para adaptar su estructura y funcionamiento a los mandatos que en materia educativa se derivan de la Constitución, que tuvo indudable trascendencias en todos los aspectos del sistema educativo incluido el profesorado. La actual Ley Orgánica de Educación carece sin duda de tal singularidad, pues, sin negarle su carácter de importante reforma, no modifica las estructuras básicas del sistema educativo, ni en cuanto a las enseñanzas establecidas, ni en cuanto al régimen de los funcionarios docentes. Cabe preguntarse pues, si la mera aprobación de una nueva Ley educativa puede entenderse como una situación excepcional que requiera una medida como la adoptada, máxime cuando la situación de los funcionarios interinos docentes ya fue abordada por la LOGSE años atrás. Resulta evidente, a la luz de la experiencia acumulada a lo largo de los últimos cuarenta años, que la situación de importantes bolsas de funcionarios interinos, especialmente en el ámbito docente, es un problema crónico derivado de un funcionamiento anormal de nuestra

32 «La finalidad de consolidar el empleo público temporal no puede considerarse a priori constitucionalmente ilegítima, ya que pretende conseguir estabilidad en el empleo para quienes llevan un periodo más o menos prolongado de tiempo desempeñando satisfactoriamente las tareas encomendadas.» STC 107/2003, de 2 de junio F.J. $5^{\circ}$.

33 Ver STC 185/1994, de 20 de junio, F.J. $3^{\circ}$. 
Administración. La presunta excepcionalidad se ha convertido, pues, en una patente de corso para justificar sistemas de acceso que degradan el derecho fundamental de acceso en condiciones de igualdad a la función pública.

2. Devaluación de la fase de oposición en el sistema transitorio de la LOE.

El sistema excepcional de acceso previsto en la disposición transitoria decimoséptima de la LOE, tiene su desarrollo normativo en el R.D. 276/2007, de 23 de febrero, por el que se aprueba el reglamento de ingreso, accesos y adquisición de nuevas especialidades en los cuerpos docentes y concretamente en el título VI del mencionado Real Decreto. El artículo 58 de la mencionada disposición establece las líneas maestras del sistema de acceso:

«Durante los años de implantación de la Ley Orgánica 2/2006, de 3 de mayo, de Educación, que conforme a la disposición adicional primera será de cinco años, el ingreso a la función pública docente se realizará mediante un procedimiento selectivo en el que, en la fase de concurso se valorarán la formación académica y, de forma preferente, la experiencia docente previa en los centros públicos de la misma etapa educativa, hasta los límites legales permitidos. La fase de oposición, que tendrá una sola prueba, versará sobre los contenidos de la especialidad que corresponda, la aptitud pedagógica y el dominio de las técnicas necesarias para el ejercicio de la docencia.»

Por un lado el procedimiento de acceso privilegia a los funcionarios interinos al valorar de forma preferente la experiencia docente «hasta los límites legales permitidos» ${ }^{34}$. Por otro lado se devalúa la fase de oposición mediante diversos mecanismos que reseñaremos a continuación.

La oposición constará de una prueba estructurada en dos partes. La parte A tendrá por objeto la demostración de los conocimientos específicos de la especialidad para impartir docencia. La parte B, que también se divide en dos partes, tendrá por objeto la comprobación de la aptitud pedagógica del aspirante y de las técnicas necesarias para el ejercicio docente. La parte B.1 consistirá en la presentación de una unidad didáctica y su defensa ante el tribunal. La parte

34 El art. 61.3 del EBEP estableció que a la valoración de los méritos deberá otorgarse una "puntuación proporcionada» que no determine en ningún caso, por sí misma el resultado del proceso selectivo. De enorme trascendencia en la determinación del límite cuantitativo en la valoración de los méritos es la STC 67/1989, de 18 de abril F.J. $4^{\circ}$, ya analizada en un apartado anterior. 
B.2 consistirá en la preparación, exposición y defensa ante el tribunal de una unidad didáctica de la programación presentada por el aspirante. La parte A se valorará en un $40 \%$ de la nota de oposición, mientras a la parte B le corresponde el $60 \%$ restante.

Lo novedoso del sistema, respecto a los sistemas habituales de acceso a la función docente ${ }^{35}$, es que las distintas pruebas no son eliminatorias. Ello supone que el aspirante que no supere la parte A, que tiene por objeto la demostración de los conocimientos específicos de la especialidad para impartir docencia, no queda eliminado, si obtiene en la parte B los puntos necesarios para alcanzar el cinco. Resulta evidente que para un funcionario interino no será demasiado difícil la presentación y defensa de una programación didáctica, tarea para la que puede contar previamente con ayuda ajena. Pero lo realmente sorprendente es que pueda aprobar la fase de oposición un aspirante a una función docente que sea calificado con un cero en la prueba de acreditación de los conocimientos propios de su especialidad. Sin duda, nunca se había llegado tan lejos en los procesos de desvalorización de las oposiciones y, por ende, del principio constitucional de capacidad.

Por otro lado, la parte A de la oposición, consiste en el desarrollo por escrito de un tema elegido por el aspirante entre un número de temas extraídos al azar. Un sencillo procedimiento para abaratar las oposiciones, previsto también en el sistema transitorio de acceso, es incrementar el número de temas extraídos al azar para que el aspirante goce de más posibilidades. Así en una especialidad cuyo temario sea de 51 temas se extraerán cinco bolas al azar entre las que el aspirante escogerá el tema a desarrollar.

Todas estas prácticas y otras similares han sido objeto de dura crítica por parte de la doctrina. Así el profesor PARADA ${ }^{36}$ sostiene que estas fórmulas no son sino formas encubiertas de conversión de funcionarios interinos en funcionarios de carrera, "a través de unas oposiciones simuladas o si se prefiere abaratadas en la exigencia de conocimientos y rigores de pruebas». Cabe preguntarse hasta donde podría llegarse con estos sistemas sin que se vea alterada la esencia misma de los principios constitucionales de igualdad, mérito y capacidad.

${ }^{35}$ El propio Real Decreto 276/2007 establece en el sistema ordinario de acceso regulado en el art. 21, que las pruebas tendrán carácter eliminatorio.

36 Parada Vázouez, J. R., en Derecho Administrativo II, Organización y empleo público, Madrid: Marcial Pons, 2007, pág 484. 
3. Exención de prueba selectiva a los funcionarios interinos. ¿vulneración del derecho a la igualdad?

El RD 276/2007 que regula el régimen transitorio de ingreso a la función docente, establece unas normas reguladoras del procedimiento de acceso que es necesario estudiar por ser, cuanto menos a nuestro juicio, sospechosas de vicios de inconstitucionalidad por vulneración del art. 23.2 CE. El artículo 61 que regula la fase de oposición establece, en relación al ejercicio B.2, consistente en la preparación, exposición y defensa de una unidad didáctica, la siguiente regla de procedimiento:

«Las Administraciones educativas, en el caso del profesorado interino que estuviera en activo, conforme se determine en sus respectivas convocatorias, podrán sustituir este ejercicio por un informe, que a tal efecto y a instancias del aspirante elaboren dichas Administraciones, en el que se valoren los conocimientos del aspirante acerca de la unidad didáctica. En dicho informe que, de conformidad con las funciones atribuidas a los órganos de selección en el artículo 6 de este Reglamento, será juzgado, valorado y calificado por el Tribunal correspondiente, deberá acreditarse, al menos, la concreción de los objetivos de aprendizaje que se han perseguido en las unidades didácticas, sus contenidos, las actividades de enseñanza y aprendizaje que se plantean en el aula y sus procedimientos de evaluación.»

Es decir, que en aquellas Comunidades en que así se decida, el profesor interino que estuviera en activo podrá elegir entre realizar la prueba consistente en la exposición y defensa de una unidad didáctica ante el tribunal, o bien sustituirla por un informe en el que se acredite una serie de cuestiones referidas a la programación presentada en la parte B.1 de la oposición. Como podrá entenderse dicha formulación deja abiertos muchos interrogantes que las singulares convocatorias de cada Comunidad Autónoma han de concretar. No procede aquí analizar cómo ha desarrollado este confuso precepto cada comunidad autónoma, pues sería muy prolijo. Nos limitaremos a reseñar algunas cuestiones de trascendencia que han tenido desarrollo reglamentario en las distintas convocatorias. Por ejemplo, en algunas convocatorias, la posibilidad de acogerse al informe se reserva a quienes se encuentren en servicio activo, como funcionario interino, siendo requisito que el nombramiento haya sido en la misma plaza y en el mismo cuerpo al que opta el aspirante y con una prestación de servicios mínima de seis meses. En otras convocatorias sólo se admite la validez del informe emitido por la propia Comunidad Autónoma convocante. Otro aspecto a destacar es que los informes no son elaborados por el órgano de selección del proceso selec- 
tivo, sino por una comisión ad hoc designada por la Administración. El tribunal se limitará a calificar el informe no la actuación del opositor $^{37}$.

37 Como ejemplo transcribimos Resolución de 13 de marzo de 2008, de la Viceconsejería de Modernización y Recursos Humanos del Principado de Asturias, por la que se convocan procedimientos selectivos para acceso e ingreso en los Cuerpos docentes a que se refiere la Ley Orgánica 2/2006, de 3 de mayo, de Educación, en lo relativo a este polémico informe:

Sustitución del ejercicio B.2: La preparación y exposición de una unidad didáctica podrá ser sustituida, a petición del aspirante, por un informe en el que se valoren los conocimientos del aspirante acerca de la unidad didáctica.

Para ello, el aspirante deberá adjuntar a su solicitud de participación, debidamente cumplimentado, el anexo VI. Esta opción voluntaria no podrá ser modificada en ningún momento posterior del proceso selectivo.

Estarán legitimados para solicitar el informe, los aspirantes que formalizando su solicitud de acuerdo con esta convocatoria reúnan los siguientes requisitos:

- Encontrarse en servicio activo, como funcionario interino, siendo requisito que el nombramiento haya sido en la misma plaza y en el mismo cuerpo al que opta el aspirante y con una prestación de servicios mínima de 6 meses, contado todo lo anterior al término del plazo de presentación de solicitudes de participación en el presente procedimiento selectivo.

Se entenderá que cumplen estos requisitos, los aspirantes que, por haberse acogido a situaciones amparadas por la normativa vigente, no se encuentren ocupando la plaza adjudicada para el referido curso 2007/2008 o, quienes teniendo un nombramiento para todo el curso 2007/2008, hayan sido removidos de ella por circunstancias derivadas de la planificación educativa u otras circunstancias sobrevenidas.

Aquellos aspirantes que no cumplan los requisitos citados para la emisión del informe y lo hayan solicitado, figurarán expresamente en la resolución por la que se apruebe la lista provisional de admitidos y excluidos con indicación de tal extremo, debiendo, en consecuencia realizar la parte B.2 de la prueba.

Igualmente si por causas ajenas a la Administración convocante, ésta no dispusiera de acreditación del cumplimiento de los requisitos de un aspirante, éste deberá realizar la parte B.2 de la prueba.

Con el fin de garantizar la objetividad e imparcialidad en la elaboración del informe, los criterios objetivos se hacen públicos en el anexo VI, debiendo acreditarse, la concreción de los objetivos de aprendizaje que se han perseguido en las unidades didácticas, sus contenidos, las actividades de enseñanza y aprendizaje que se plantean en el aula y sus procedimientos de evaluación: Para la evaluación del informe se seguirá el siguiente procedimiento:

a) Solamente tendrán validez los informes emitidos por esta Comunidad Autónoma.

b) Los informes serán elaborados por una Comisión formada por tres miembros. Estará presidida por un funcionario del Cuerpo de Inspectores de Educación o del Cuerpo a extinguir de Inspectores al Servicio de la Administración Educativa y dos funcionarios del cuerpo al que opten los aspirantes

c) La Dirección del Instituto Asturiano de Administración Pública «Adolfo Posada», una vez recibidas las solicitudes de los aspirantes, acompañadas de la correspondiente unidad didáctica y verificado el cumplimiento de los requisitos, enviará esa documentación a la correspondiente Comisión.

d) La Comisión correspondiente elaborará los respectivos informes antes del 25 
Un procedimiento de esta naturaleza, inédito en la historia de los sistemas de acceso a la función pública docente, merece un análisis a la luz de la jurisprudencia constitucional estudiada. En primer lugar cabe plantearse si este sistema otorga ventajas a los interinos sobre aquellos que no lo son. Parece evidente que así es, pues se exonera al funcionario interino de la exposición y defensa de una unidad didáctica ante el tribunal, prueba que tendrán que superar el resto de los opositores. Podría argumentarse que esta prueba es sustituida por otra, la realización de un informe sobre su programación, aunque parece evidente que ambas pruebas no tienen el mismo carácter ni dificultad. No obstante donde si se manifiesta claramente una ventaja del opositor interino es en la posibilidad de éste de optar por la realización de la prueba o por su sustitución por el informe. Esta posibilidad de escoger una u otra prueba es una manifestación palmaria de una ventaja en la fase de oposición de la que no gozan los que no son interinos.

La primera cuestión que hay resaltar es que este tratamiento privilegiado no viene establecido en la Ley, sino en normas reglamentarias, en concreto en un Real Decreto del Ministerio de Educación y Ciencia y en las respectivas convocatorias de procesos selectivos aprobadas por cada Comunidad Autónoma. A este respecto hay que recordar que, como señala el Tribunal Constitucional, la Constitución reserva a la Ley la regulación de las condiciones de ejercicio del derecho, lo que entraña una garantía de orden material que se traduce en la imperativa exigencia de predeterminar cuales hayan de ser las condiciones para acceder a la función pública ${ }^{38}$. Bien es cierto que el propio Tribunal matiza esa postura cuando afirma que «las disposiciones reglamentarias, cuando así lo requiera la Ley, pueden colaborar con ésta para complementar o particularizar, en aspectos instrumentales y con la debida sujeción, la ordenación legal de la materia reservada ${ }^{39}$. Sin embargo en el caso que nos ocupa no pa-

de junio de 2008, debiendo ser remitidos en ese plazo a la Comisión de Selección de la especialidad correspondiente, quien acusará recibo de los documentos.

e) La Comisión, previa cita concertada, con un mínimo de cuarenta y ocho horas, podrá entrevistar al aspirante en relación con los aspectos contenidos en la unidad didáctica presentada por el interesado.

f) El Presidente o Secretario de la Comisión de Selección serán responsables de su custodia hasta el momento en que los entreguen a los Presidentes de los Tribunales correspondientes, para su valoración e incorporación a la calificación global y final de la fase de oposición.

38 Ver, entre otras, las SSTC 48/1998, de 2 de marzo, F.J. 7, 73/1998, de 31 de marzo, F.J. 3, y 138/2000, de 29 de mayo, F.J. 6.

39 STC 138/2000, de 29 de mayo, F.J. 6. 
rece que la disposición reglamentaria se limite a completar o particularizar lo dispuesto en la Ley, sino más bien introducir procedimientos privilegiados para los funcionarios interinos no contemplados en la propia Ley. Ello nos lleva a plantearnos si ello no supone una vulneración del art. 23.2 CE, pues como dice el Tribunal Constitucional, este puede ser vulnerado cuando por vía reglamentaria «se introduzcan nuevos requisitos condiciones que limiten el acceso a la función pública a determinados ciudadanos o grupos sin contar para ello con la necesaria habilitación legislativa, excluyendo del goce de un derecho a los que la Ley no excluyó.» (STC 138/2000, de 29 de mayo, F.J 6).

Procede también preguntarse si esta diferenciación normativa tiene una justificación constitucional en relación al fin perseguido. Respecto a esta cuestión ya hemos visto que en reiteradas sentencias ${ }^{40}$ el Tribunal considera un fin constitucionalmente legítimo la reducción del porcentaje de funcionarios interinos, que es precisamente la finalidad manifestada expresamente por la disposición transitoria objeto de estudio. Ahora bien, cabe cuestionarse si tal desigualdad de trato resulta justificada y razonable de acuerdo con criterios o juicios de valor generalmente aceptados. Existen serias dudas de que un sistema como el analizado no suponga una desigualdad de trato arbitraria e irrazonable, pues la condición de que todos los aspirantes estén sometidos a las mismas pruebas y normas de procedimiento constituye, a nuestro juicio, parte del contenido esencial del derecho fundamental, consagrado en el art. 23.2 CE, sin el cual éste no sería reconocible. El Tribunal Constitucional, a lo largo de la doctrina que hemos ido desgranando a lo largo de este trabajo, ha respaldado sistemas que concedían ventajas a los funcionarios interinos, mediante una valoración preferente de la antigüedad o a través del abaratamiento de la fase de oposición. En ningún caso el Alto Tribunal ha avalado sistemas que establezcan normas de procedimiento diferenciadas y ventajosas para los funcionarios interinos, excepto en el caso excepcional de las oposiciones restringidas.

A mayor abundamiento habría que justificar por qué tienen derecho a este privilegio sólo los interinos que acrediten un prestación de servicios mínima de seis meses y no gozan de la misma los que tengan acreditado un tiempo inferior. También cabría preguntarse si el hecho de admitir sólo el informe emitido por la propia Comunidad Autónoma no supone una discriminación injustificada de

${ }^{40}$ Ver entre otras las SSTC 67/1989, de 18 de abril, 185/1994, de 20 de junio y 27/1991, de 14 de febrero. 
aquellos interinos que presten servicios fuera de esa concreta Comunidad Autónoma. Igualmente es cuestionable si las normas relativas al los órganos de selección, que tan importantes son en la efectividad del derecho consagrado en el art. 23.2 CE, no se ponen en cuestión con la irrupción de un órgano ajeno al proceso de selección que elabora el reseñado informe. En suma este singular procedimiento de acceso presenta numerosos interrogantes sobre su compatibilidad con los principios constitucionales que rigen el acceso a la función pública.

\section{CONCLUSIONES}

Un problema recurrente en la Administración Pública española ha sido la utilización, en muchos casos abusiva, de la contratación temporal de personal, que ha generado periódicamente grandes bolsas de funcionarios interinos. El legislador, presionado por estos colectivos y especialmente por las organizaciones sindicales, ha recurrido con demasiada frecuencia a sistemas de acceso que, con el objetivo de resolver el problema de la precariedad de este personal, establecieron ventajas para los aspirantes que tuvieran la condición de interinos.

$\mathrm{El}$ acceso a la función pública en el ámbito docente no universitario ha padecido durante estos años, las mismas prácticas restrictivas al derecho a la igualdad que se han señalado con carácter general para el resto de la función pública. La formación periódica de grandes bolsas de interinos ha sido un problema irresoluto que ha condicionado de múltiples maneras los sistemas de acceso, en detrimento siempre de los principios constitucionales de igualdad, mérito y capacidad.

El Tribunal Constitucional, si bien reconoce que estas prácticas consagran una desigualdad en el acceso, las ha venido avalando reiteradamente so pretexto de tratarse de un remedio excepcional que persigue una finalidad constitucionalmente legítima, cual es la consolidación del empleo temporal de los funcionarios interinos en aras de la eficacia de la Administración.

Las pruebas restringidas, que fueron proscritas por el Tribunal Constitucional en el año 1991, estuvieron sin embargo plenamente vigentes durante años en el ámbito docente. En esta misma línea se legislaron sistemas de acceso que, si bien estaban abiertos a la participación de todos los ciudadanos que reunieran los requisitos generales, colocaron a los interinos en una situación de ventaja al va- 
lorar de manera preferente como mérito los servicios prestados a la Administración. Así ocurrió con el sistema transitorio de acceso regulado en la LOGSE. El Tribunal Constitucional, si bien reconoció la existencia de una evidente desigualdad de trato, la justificó en el carácter excepcional de la nueva ley y en la necesidad de consolidar la gran cantidad de empleo precario existente en la función docente. En resumen, las desigualdades en el acceso a la función docente han sido frecuentes, si bien, en la mayor parte de los casos, han sido amparadas por la jurisprudencia del Tribunal Constitucional.

Ante esta doctrina del Alto Tribunal cabe cuestionarse si es aceptable el sacrificio de un derecho fundamental, como el consagrado en el art. 23.2 CE, en aras de una pretendida eficacia administrativa, máxime cuando la situación derivada de las grandes bolsas de interinos es fruto de un incorrecto funcionamiento en la contratación de nuestras Administraciones Públicas.

Lo que si resulta claramente criticable es la presunta excepcionalidad de tales sistemas de acceso que reiteradamente viene amparando el Tribunal Constitucional. Si bien la creación de las nuevas Administraciones Autonómicas supuso una situación nueva y única, estas prácticas han venido repitiéndose desde entonces con demasiada frecuencia. En suma, lo que no termina de ser aceptable es que la excepción se haya transformado en regla, degradando con estas prácticas el derecho fundamental a acceder en condiciones de igualdad a la función pública.

Prueba palmaria de ello es el sistema de acceso a la función docente que ha venido operando en los últimos años amparado por la LOE. Como hemos visto reproduce amplificadas muchas de las prácticas restrictivas de la igualdad señaladas, en favor de los funcionarios interinos. Estamos de nuevo ante un sistema transitorio y excepcional que la Ley justifica en la necesidad de reducir el alto porcentaje de funcionarios interinos en el ámbito docente. Lo que sin duda es criticable, y contrario a espíritu de la jurisprudencia constitucional, es la presunta excepcionalidad que invoca la ley, que tal parece se ha convertido en una patente de corso para justificar sistemas de acceso que degradan el derecho a la igualdad en el acceso.

En resumen, transcurridos ya más de treinta años desde la aprobación de nuestro texto constitucional, podemos afirmar que en el ámbito docente casi la mitad de ese periodo ha contemplado sistemas excepcionales de acceso favorecedores de los funcionarios interinos, con evidente sacrificio del derecho a acceder en condiciones de igualdad a la función pública. Por ello, y a modo de conclusión final, 
coincidimos con el profesor SÁNCHEz MoRóN ${ }^{41}$ cuando afirma que si bien es cierto que nuestra sociedad ha dado pasos de gigante hacia la igualdad jurídica en las últimas décadas en muchos aspectos de las relaciones públicas y privadas, la igualdad en el acceso a la función pública «es todavía una asignatura pendiente, un test para nuestra democracia».

41 Sánchez Morón, M., "Igualdad, mérito y capacidad en el empleo público», en VV.AA., El principio de igualdad, Madrid: Dykinson 2000, pág. 146. 